IRA International Journal of Management \& Social Sciences ISSN 2455-2267

Vol. 14, Issue 02 (Special Issue) pg. 11-16.

International Conference on Wellbeing: Lifespan Perspectives $छ$ Practices for

Sustainable Communities, 2019.

\title{
Empathy Enhances Wellbeing in Interpersonal Relationships across Lifespan
}

Joseph Mariadhas

Research Scholar at the Research and Development Centre, Bharathiar University, Coimbatore, under the supervision of Dr S. John Michael Raj, Former Professor, Department of Psychology, Bharathiar University at Coimbatore. He is a faculty member at St. Joseph's College, Jakhama in Nagaland, India.

DOI: $10.21013 /$ jmss.v14.n2sp.p2

(C) Authors.

Type of Review: Peer Reviewed under the Responsibility of the conference's Scientific Committee.

Disclaimer: The copyright to this work is retained by the authorship. This work contains the opinions Ev views of the authorship solely and the same are not the views or opinions of the IRA. IRA disclaims of any harm or loss caused due to the published content to any party. 


\begin{abstract}
The healthy and happy human living revolves around establishing and maintaining stable relationships with each other. The life experiences pose whether these meaningful relationships are considered important for the wellbeing of individuals and communities. People constantly strive for cordial interactions with others, on one side, to avoid psycho-physiological damages such as loneliness and disapproval from others and on the other side, to shape their life meaningfully and grow purposefully. Empathy has been considered a vital component of one's social cognition that contributes to one's ability to understand and respond adaptively to others' emotions that promotes prosocial behaviour in interpersonal relationships and communications. Empathy enhances cognitive abilities and emotional stability thus promoting well being in interpersonal relationships (Preston \& de Wall, 2002). The human qualities, for instance, attraction, love, kinship, friendship, jealousy, betrayal, forgiveness, communication, conflict and aggression are either positively or negatively connected to human relationship domain and vital for the wellbeing at all levels. And, for upholding wellbeing and interpersonal relationships, the predominant and promising dynamic seems to be the psychological component of empathy. The present presentation pungently brings out the conceptual details on the concept of empathy along with its imperative role in enhancing interpersonal affinity or relationships in enhancing wellbeing in general. This paper is presented to establish that empathy enhances the interpersonal relationship and well-being across the life span.
\end{abstract}

Key Words: Empathy, Wellbeing, Interpersonal Relationship

\title{
Discussion
}

The scholarly research on wellbeing is becoming increasingly important in most of the social sciences. The literature identifies a number of elements as contributors to wellbeing like the quality of life, happiness, life satisfaction, and prosperity and they are also often used interchangeably with wellbeing. Wellbeing is considered as one of the major components of human growth and development thus enhancing fulfilment and satisfaction across the lifespan. Human beings are not machines. We need people to talk to and share our feelings. We are social animals and we need friends around. Our social relationships are formed for more reasons than just the nature of our species. Relationships are a part of life and they help to fulfil the emotional and physical needs of one another. People with strong, healthy interpersonal relationships tend to be healthier and experience less stress from life challenges (Simpson \& Rholes, 1994). The theory of attachment defines attachment as a deep and lasting bond connecting people across distance and through time. Adaptively, attachment enhances survival, especially in infancy when the child is completely dependent on its mother and other caregivers. The caregivers' bond with the child encourages them to fulfil the infant's needs and thus provides continuation of the species. We don't grow out of this bonding behaviour and continue to benefit throughout our lives from our relationships (Bowlby, 1969, 1982). However, not all interpersonal relationships are the same. These bonds are defined by different expectations between the individuals and the context of their relationships. There are four basic categories of these relationships, separating our bonds into the family, friends, romantic partners, and colleagues. This has been further conceptualized as four attachment styles namely secure, preoccupied, dismissive, and fearful (Bartholomew \& Horowitz, 1991).

The life experiences pose whether these meaningful relationships are considered important for the well-being of individuals and communities. Empathy has been considered a vital component of one's social cognition that contributes to one's ability to understand and respond adaptively to others' emotions that promotes prosocial behaviour in interpersonal relationships and communications. Empathy enhances cognitive abilities and emotional stability thus promoting well being in interpersonal relationships (Preston \& de Wall, 2002). The human qualities, for instance, attraction, love, kinship, friendship, jealousy, betrayal, forgiveness, communication, conflict and aggression are either positively or negatively connected to human relationship domain and enhances well-being at all levels. And, for upholding wellbeing and interpersonal relationships, the predominant and promising dynamic seems to be the psychological component of empathy. This paper is presented to establish that empathy enhances the interpersonal relationship and well-being across the life span.

\section{Empathy}

Empathy has been defined as the action of understanding, being aware of, being sensitive to, and vicariously experiencing the feelings, thoughts, and experience of another of either the past or present without having the feelings, thoughts, and experience fully communicated in an objectively explicit manner (Merriam-Webster Dictionary, 2018). Empathy is the ability to share another person's feelings and emotions as if they were their own (Collins English Dictionary, 2018). Empathy is the ability to share someone else's feelings or experiences by 
imagining what it would be like to in that person's situation (Cambridge English Dictionary, 2018). Empathy is the capacity to understand or feel what another person is experiencing from within their frame of reference, i.e., the capacity to place oneself in another's position (Bellet, Paul, Michael \& Maloney, 1991). Empathy has many definitions that encompass a broad range of emotional states, including caring for other people and having a desire to help them; experiencing emotions that match another person's emotions; discerning what another person is thinking or feeling (Pijnenborg, Spikman, Jeronimus \& Aleman, 2012); making less distinct the differences between the self and the other (Hodges \& Klein, 2001). Empathy can be defined as the capacity to recognize the bodily feelings and movements of another associated with their facial expressions and the ability to feel and share another person's emotions.

\section{Wellbeing}

According to the dictionary, well-being is a contented state of being happy and healthy and it is concerned with a person's physical and mental soundness. Though the words well-being and happiness are used interchangeably, however, well-being is a more comprehensive term that refers to optimal psychological experience and functioning and it has been extensively studied in the field of psychology over the past quarter century (Deci \& Ryan, 2008). The Oxford dictionary defines wellbeing as "the state of being or doing well in life; happy, healthy, or prosperous condition; moral or physical welfare of a person or community (Oxford English Dictionary, 1989). The World Health Organization (WHO) has not specifically identified the meaning of wellbeing or wellness but does use the term wellbeing within its definition of health as a state of complete physical, mental and social well-being and not merely the absence of disease or infirmity (WHO, 1948). In the field of psychology, conceptual thinking in relation to the term wellbeing appears to be somewhat privileged. Wellbeing has been defined within the concept of subjective wellbeing incorporating both cognitive and affective evaluations of a person's life and includes happiness and satisfaction with life (Duckworth, Steen Seligman, 2005).

\section{Interpersonal Relationships}

A strong bond between two or more people refers to the interpersonal relationship and is a strong, deep, or close association or acquaintance between two or more people that may range in duration from brief to enduring. This association may be based on inference, love, solidarity, regular business interactions, or some other type of social commitment and a close relationship as one that is strong, frequent, and with diverse interdependence that lasts over a considerable period of time (Kelley, Berscheid, \& Christensen, 1983). Interpersonal Relationship is a close association or acquaintance between two or more people. The interpersonal relationship can also be defined as the social association, connection or affiliation between two or more people.

\section{The Conceptual Features of Empathy}

The feeling of understanding and sharing another person's experience is a unique emotional factor fostered as empathy. In fact, it is the capacity to understand or feel what a person is experiencing from within their frame of reference, i.e., the capacity to place oneself in another's position. Psychologists have candidly stated that empathy is the experience of understanding another person's condition from their perspective. It is the link between self and others leading people to understand what others are experiencing as if they were feeling it themselves. Empathy goes far beyond sympathy, which might be considered 'feeling for' someone. Empathy, instead, is 'feeling with' that person, through the use of cognitive factors of thoughts and imaginations. The exploration of empathy in the aspect of interpersonal relationship indicates to improve social abilities, a proper understanding of emotions, the improvement of communication ability, greater sensitivity to other people's feelings or better understanding of the consequences of one's own behaviour. It is making up emotional, cognitive and executive decision people make in order to have the abilities to accept another person's perspective (Laura López, 2016). Showing such an emotional response of compassion and concern for someone's need plays an essential role in the development and maintenance of cordial connection leading to satisfaction in one's life (Dijikstra, 2014).

\section{The Conceptual Features of Interpersonal Relationship}

One of the most important aspects of human life is a relationship. People naturally and normally seek out physical and emotional nurturing. The researchers have defined the term very methodically with ample elaborations. It is a strong, deep, or close association or acquaintance between two or more people either for a brief or extended periods. Though the relationship between each other emanates from various psychosocial features its ultimate goal is to establish both individuals as well as the societal progress. Again, living a connected life contributes to the reduction of stresses and strains of life and facilitates the emergent of the best possible performance. Thus, 
interpersonal skills are vital when trying to develop a relationship with another person (Berscheid, 1999). Social exchange theory and Rusbult's investment model shows that relationship satisfaction is based on the rewards they receive, the costs they incur, and the between these two (Fincham, \& Beach, 2010). When two persons start relating to each other both of them start mutually supporting and get affected each other. In society, each individual establishes a relationship with so many people for various conditions and sustaining the relationships important for positive living.

The positive bond with others begets social support and enhances human potentials. In the hierarchical needs theory of Abraham Maslow, humans need for love and acceptance from social groups like family, peer groups and others in the society play a pivotal role in the growth and development process of all human beings. In fact, the capacity to the empathetic relationship is innately ingrained in all human beings it has to be acquired and practised constantly for keeping interpersonal relationships intact. Retaining a lifelong interpersonal relationship with a quality number of people assists individuals to express and experience positive and prosperous emotional behaviour patterns in their lives. Therefore, the interpersonal relationship is a skill or ability to build rapport with others who have similar interests and goals and thus enable people to establish a special bond, share positive feelings and trust one another and maintain the friendship that is established. In general interpersonal relationship is healthy for human endeavours for enhancing the human potentials to the maximum point. Living in group enhanced strength and ensured safety for early human beings. For early humans, being in a group was a way to enhance their strength and ensure their safety. Apart from this, being together is inherently available quality. Again, the human brain is designed to guide an individual to be sociable, and because of this the social interactions and forming relationships become significant for human development. Hence, interpersonal relationships are an essential facet of human nature and cannot be separated from humans. This is the basic reason even in today's fast developed society though people are engaged in a variety of activities, living in relationship remains intact.

A number of theories explained the nature of interpersonal relationships as a strong association amongst individuals and is essential for individuals to share a healthy relationship with each other to create a positive ambience in their lives. The social exchange theory of George Casper Homans (1958) emphasized the feelings and emotional capabilities contribute to a successful and long-lasting relationship. The expectations and experiences are meaningfully fulfilled the relationship become meaningless and sustains. Otherwise, the relationship gets disintegrated and leads to failure. And, uncertainty reductions theory of Berger and Calabrese (1974) explained the relationship between individuals as passing through various stages to reduce the level of uncertainty and their compatibility level in order to enter into either positive relationship of separation. Further, sustaining and growing in interpersonal relationships has a potential quality of increasing psychological well-being and decreasing physical illness of individuals (Wills, 1985). It again, enhances developmental competencies, such as managing the emotions, increasing interdependence, developing maturity, establishing identity, cultivating a sense of purpose and build up integrity as the epitome of human life (Chickering \& Reisser, 1993). Therefore, it becomes evident that the interpersonal relationship is an essential component for both the well-being and growth of human beings.

\section{Dynamics of Empathy Enhancing Wellbeing in Interpersonal Relationships}

It has been time and again proved that the meaningful and purposeful human life seems to be established by many factors and among them, empathy occupies a special place. This is a unique topic of growing concern in a variety of disciplines. The investigation carried out in diverse fields on empathy strongly advocate it is the capacity to understand and share feelings with others, and remains as a vital function for establishing social communication, connection, and interaction (Decety and Jackson, 2004). Even for mediating the development and acquisition of appropriate social behaviours on a daily basis (de Vignemont \& Singer, 2006; Li \& Han, 2010). In medical fields, it has been understood that the neural bases of empathy systematically tune the emergent of positive emotions in social living by the individuals (Jabbi, 2007; Takahashi, 2009; Morelli \& Lieberman, 2013). It has been revealed that individuals with higher levels of empathy were able to resolve the conflict in their relationships more successfully than others (Susan Whitbourne, 2012). And it is further emphasized that empathy is a critical component for facilitating pro-social behaviours and moderates aggressive behaviour (Eisenberg \& Miller, 1988); assists in establishing and maintaining friendships (Del Barrio, Aluja\& Garcia, 2004); enhances satisfaction in intimate relationships (Long, Angera \& Hakoyama, 2008); improves the quality of family relationships and is positively associated with family cohesion, parental support, and communicative responsiveness (Henry, Sager \& Plunkett, 1996); increases helping behaviours (Jolliffe \& Farrington, 2007); reduces children's aggressive and acting-out behaviors (McMahon \& Washburn, 2003) and clearly improves relationship status between individuals and makes the world a place for worth living. 


\section{Establishing Wellbeing through Empathy in Interrelationships}

The dynamic functioning of empathy on human behaviour in general and interpersonal relations, in particular, recommends that it has to be inculcated and improved for a healthy and wealthy living. Researchers have recommended various steps to enhance empathetic qualities to ascertain interrelationships. One of these specific and special working modules is presented below.

Active Listening- Totally absorbed when someone is speaking is the starting point of developing empathy. Listening aids in understanding the real and complete picture of the situations of the other person. It has to inculcate in everyone's mind and practice. By constant training and concentrating on another person's ideas one a gradually improve their listening skills. If the work at hand is properly carried out the next person would give the feedback. And the comments of others will give the direction one should focus. Hence, listening to others remains as the first step (Kingston \& Medlin (2005).

Challenging one's Prejudices and Stereotypes -The errors in cognition triggers negative views on somebody or something and leads to express negative behaviour. As a step to curtain these dangerous things, everyone has to come out of their comfort zone. Try to notify the persons who are quite different than oneself. Learn the areas where they are different. Then find out the reasons for the variations. Spending quality time periodically on analyzing the differences will clarify the conditions and that will move one person towards another easily (Boag \& Carnelley, 2016).

Developing Curiosity about Others- Opening the eyes every day and start watching the people around in the world. Mainly, people who assist in day-to-day activities are to be keenly watched. Raising questions in the mind that how do they come to these types of the job? And why they have come? These types of questioning will give a clearer picture of others and ultimately the person who raises the question. The curious questions will give a quite surprising answer about others and change the view of them accordingly (Lawrence Bookbinder, 1971).

Spending Quality Time with Others - This step has to parts. The first one is to observe the living conditions of others. How much amount do they get and spend? This is a valuable experience of life one can understand. Easy to get the plight of others is to spend some time closely with others and it will give hands-on experience about others (Larson, E. B., \& Yao, X. (2005).

Sharing with Others - It means to exchange some of the inner feelings with others. Sharing of both the happy as well as one's aspiration with others even for few seconds strengthens the tie between each other. The continuance of sharing with the same persons or with whomsoever one interacts in a longer time permits to exchange still more information between them. In due course, their relationship would get strong and life becomes meaningful (Jolliffe\& Farrington, 2007).

\section{Conclusions}

The researchers in the field of interpersonal relations established certain facts that human beings are in nature undergo changes in their thinking, feeling and behaving. Varied factors contributed to the change. Living and leading a purposeful and meaningful life among the different mindsets requires special skills. One among them is the empathy that is, the feeling one with others. It is a social skill that needs to be practised constantly to break the negative mindset and grow in positive qualities for making one's life momentous. The specific and special steps that go in for initiating such a positive quality are: improving the active listening, challenging the attributes of prejudices and stereotypes, facilitating curiosity in others, spending quality of time and start sharing. The steady and stable accomplishment of these qualities will make human life enjoyable and excited. 


\section{References}

[1]. Barrio, V. D., Aluja, A., \&García, L. F. (2004).Relationship between empathy and the Big Five personality traits in a sample of Spanish adolescents. Social Behavior and Personality: an international journal, 32(7), 677-681.

[2]. Berger, C. R., \& Calabrese, R. J. (1974). Some explorations in initial interaction and beyond: Toward a developmental theory of interpersonal communication. Human communication research, 1(2), 99-112.

[3]. Berscheid, Ellen. (1999). The greening of relationship science. American Psychologist. 4.54 (4): 260-266.

[4]. Boag, E. M., \&Carnelley, K. B. (2016). Attachment and prejudice: The mediating role of empathy. British Journal of Social Psychology, 55(2), 337-356.

[5]. Bookbinder, L. J., Fox, R. E., \& Rosenthal, V. (1971).Recommended standards for psychotherapy education in psychology doctoral programs. Professional Psychology, 2(2), 148.

[6]. Chickering, A. W., \&Reisser, L. (1993). Education and Identity.The Jossey-Bass Higher and Adult Education Series.Jossey-Bass Inc., Publishers, 350 Sansome St., San Francisco, CA 94104.

[7]. Decety J. (2011). "The neuroevolution of empathy". Annals of the New York Academy of Sciences. 1231 (1): 35-45.

[8]. Decety, J., and Jackson, P. L. (2004). The functional architecture of human empathy. Behav.Cogn.Neurosci. Rev. 3, 71100.

[9]. deVignemont, F., and Singer, T. (2006). The empathic brain: how, when and why? Trends Cogn. Sci. 10, 435-441.

[10]. Dijkstra, Pieternel, Dick P.H. Barelds, Hinke A.K. Groothof, and Marnix Van Bruggen. "Empathy in Intimate Relationships: The Role of Positive Illusions." Scandinavian Journal of Psychology 55.5 (2014): 477-82.

[11]. Fincham, F.D. \& Beach, S.R.H. (2010). Of Memes and Marriage: Toward a Positive Relationship Science. Journal of Family Theory \& Review. 2: 4-24.

[12]. Henry, C. S., Sager, D. W., \& Plunkett, S. W. (1996).Adolescents' perceptions of family system characteristics, parentadolescent dyadic behaviors, adolescent qualities, and adolescent empathy. Family Relations, 283-292.

[13]. Henry, C. S., Sager, D. W., \& Plunkett, S. W. (1996).Adolescents' perceptions of family system characteristics, parentadolescent dyadic behaviors, adolescent qualities, and adolescent empathy. Family Relations, 283-292.

[14]. Hodges, S.D., \& Klein, K.J. (2001). Regulating the costs of empathy: the price of being human. Journal of SocioEconomics.

[15]. Homans, G. C. (1958). Social behavior as exchange. American journal of sociology, 63(6), 597-606.

[16]. Jabbi, M., Swart, M., and Keysers, C. (2007).Empathy for positive and negative emotions in the gustatory cortex. Neuroimage 34, 1744-1753.

[17]. Jolliffe, D., \& Farrington, D. P. (2007).Examining the relationship between low empathy and self-reported offending. Legal and Criminological Psychology, 12(2), 265-286.

[18]. Jolliffe, D., \& Farrington, D. P. (2007).Examining the relationship between low empathy and self-reported offending. Legal and Criminological Psychology, 12(2), 265-286.

[19]. Kelley, H. H., Berscheid, E., Christensen, A. et al. (1983). Close Relationships. Freeman, New York.

[20]. Kingston, S. T., \& Medlin, R. G. (2005).Empathy, Altruism, and Moral Development in Home Schooled Children. Online Submission, 16(4), 1-10.

[21]. Larson, E. B., \& Yao, X. (2005).Clinical empathy as emotional labor in the patient-physician relationship. Jama, 293(9), 1100-1106.

[22]. Li, W., and Han, S. (2010). Perspective taking modulates event-related potentials to perceived pain. Neurosci.Lett. 469, 328-332. doi: 10.1016/j.neulet.2009.12.021.

[23]. Long, E. C., Angera, J. J., \&Hakoyama, M. (2008).Transferable principles from a formative evaluation of a couples' empathy program. Journal of Couple \& Relationship Therapy, 7(2), 88-112.

[24]. McMahon, S. D., \& Washburn, J. J. (2003). Violence prevention: An evaluation of program effects with urban African American students. Journal of Primary Prevention, 24(1), 43-62.

[25]. Miller, P. A., \& Eisenberg, N. (1988).The relation of empathy to aggressive and externalizing/antisocial behavior. Psychological bulletin, 103(3), 324.

[26]. Morelli, S. A., and Lieberman, M. D. (2013).The role of automaticity and attention in neural processes underlying empathy for happiness, sadness and anxiety. Front. Hum. Neurosci. 8:160. doi: 10.3389/fnhum.2013.00160.

[27]. Pijnenborg, Spikman, J.M. Jeronimus, B.F. Aleman, A. (2012). "Insight in schizophrenia: associations with empathy". European Archives of Psychiatry and Clinical Neuroscience. 263 (4): 299-307.

[28]. Salamone, J. D., Yohn, S. E., López-Cruz, L., San Miguel, N., \& Correa, M. (2016).Activational and effort-related aspects of motivation: neural mechanisms and implications for psychopathology. Brain, 139(5), 1325-1347.

[29]. Sneed, J. R., Whitbourne, S. K., Schwartz, S. J., \& Huang, S. (2012). The relationship between identity, intimacy, and midlife well-being: Findings from the Rochester Adult Longitudinal Study. Psychology and aging, 27(2), 318.

[30]. Takahashi, H., Kato, M., Matsuura, M., Mobbs, D., Suhara, T., and Okubo, Y. (2009). When your gain is my pain and your pain is my gain: neural correlates of envy and schadenfreude. Science 323, 937-939. doi: $10.1126 /$ science. 1165604.

[31]. Wills, T. A. (1985). Supportive functions of interpersonal relationships. 